\title{
KOMPETENSI MAHASISWA FT-UNJ UNTUK MELAKSANAKAN PEMBELAJARAN DI SEKOLAH MENENGAH KEJURUAN
}

\author{
Pendidikan Teknik Elektro, Fakultas Teknik, Universitas Negeri Jakarta \\ Email : yitno_muslim@yahoo.com
}

\begin{abstract}
The objective of the research is to find the correlation between students' self concept, interest to be teachers, achievement of FT-UNJ students toward the instructional competence in vocational schools. The research was conducted in the Technical Faculty of the State University of Jakarta and the Vocational Schools by the survey method with sixty respondents which selected by simple random sampling. The data are analyzed by regression and correlation procedures. The results of the research conclude: there was positive and significant correlation between students' self concept, interest to be teachers, and achievement of FT-UNJ students with instructional competence in vocational schools in a partial and together correlation. Achievement instructional competence in vocational schools can be increased by improving the quality of students' self concept, interest to be teachers, and achievement of FT-UNJ students.
\end{abstract}

Keywords: Instructional Competence, Students' Self Concept, Interest To Be Teachers, Achievement Students.

\begin{abstract}
Abstrak
Tujuan penelitian ini untuk mengetahui keeratan hubungan antara konsep diri, minat menjadi guru, dan prestasi belajar mahasiswa FT-UNJ untuk melaksanakan pembelajaran di sekolah menengah kejuruan. Penelitian ini dilakukan di Fakultas Teknik, Universitas Negeri Jakarta dan di Sekolah Menengah Kejuruan se DKI Jakarta dengan metode survei pada sampel sebanyak 60 orang yang dipilih secara acak sederhana. Data hasil penelitian dianalisis dengan korelasi produk momen dan regresi. Hasil penelitian ini menyimpulkan bahwa ada hubungan positif dan signifikan antara konsep diri, minat menjadi guru, dan prestasi belajar dengan kompetensi mahasiswa FT-UNJ untuk melaksanakan pembelajaran di sekolah menengah kejuruan, baik secara sendiri-sendri maupun bersama-sama. Kompetensi mahasiswa FT-UNJ untuk melaksanakan pembelajaran di sekolah menengah kejuruan dapat ditingkatkan dengan meningkatkan konsep diri, minat menjadi guru, dan prestasi belajar.
\end{abstract}

Kata Kunci: Kompetensi Pembelajaran Di SMK, Konsep Diri, Minat Menjadi Guru, Prestasi Belajar.

\section{PENDAHULUAN}

Semua negara termasuk Indonesia terus berusaha untuk menjadi negara maju dalam segala aspek, baik sosial ekonomi, seni budaya maupun ilmu pengetahuan dan teknologi. Kkemajuan sebuah negara ditentukan oleh dua faktor utama, yakni: (1) ketersediaan sumber daya alam (SDA), yakni: bahan tambang, luas wilayah darat dan laut, tingkat kesuburan hutan dan lahan pertanian; dan (2) mutu sumber daya manusia (SDM). Meskipun kedua sumber daya itu sama-sama penting, namun mutu sumber daya manusia lebih menentukan kemajuan sebuah negara. Contoh, Jepang merupakan negara kecil yang miskin sumber daya alam, karena tidak mempunyai hasil tambang maupun hasil hutan. Meskipun demikian negara itu mempunyai sumber daya manusia yang bermutu, dan mempunyai rasa nasionalisme yang tinggi, pekerja keras, dan sangat disiplin sehingga Jepang muncul menjadi salah satu negara maju sejajar dengan Amerika Serikat dan negara-negara Eropa Barat. Indonesia merupakan negara besar yang kaya sumber daya alam, yakni hasil tambang dan hasil hutan, namun karena mutu SDM masih rendah maka Indonesia merupakan negara berkembang.

Mutu sumber daya manusia dapat diukur dari mutu pendidikannya. Negara-negara maju mempunyai mutu pendidikan yang lebih tinggi dibandingkan negara-negara berkembang. Mutu pendidikan di Indonesia masuk dalam kategori rendah, baik di Asia apalagi dunia. Rendahnya mutu pendidikan di 
Indonesia disebabkan oleh banyak faktor, antara lain: manajemen yang kurang profesional dan rendahnya anggaran. Apapun penyebabnya yang pasti pembangunan sektor pendidikan perlu perhatian dari semua pihak. Rendahnya mutu pendidikan di Indonesia

terjadi disemua tingkatan yakni dari tingkat sekolah dasar (SD) sampai perguruan tinggi (PT), baik di sekolah menengah umum (SMU) maupun di sekolah menengah kejuruan (SMK). Rendahnya mutu sekolah menengah kejuruan sangat dirasakan oleh dunia industry sebagai pengguna lulusan SMK. Sebetulnya dunia industri dan sekolah menengah kejuruan merupakan dua lembaga yang saling membu-tuhkan. Dunia industri membutuhkan lulusan SMK untuk mengoperasikan mesin-mesin industri yang ada di pabriknya, sementara sekolah menengah kejuruan membutuhkan dunia industri untuk menampung lulusannya. Meskipun demikian ternyata banyak lulusan dari SMK yang tidak dapat diterima di industri, karena mereka tidak mempunyai kompetensi sebagaimana yang kebutuhan oleh industri. Jadi ada kesenjangan antara kompetensi yang dimiliki lulusan SMK dengan kompetensi yang dinginkan oleh dunia industri. Djojonegoro (1994) selaku Menteri Pendidikan dan kebudayaan membuat kebijakan yang populer yakni link and macth. Kebijakan itu dimaksudkan agar ada saling keterkaitan dan kerjasama yang sepadan antara dunia industri dan sekolah menengah kejuruan.

Pendidikan sebagai suatu sistem terdiri atas sejumlah subsistem, yang saling terkait satu sama lain, yakni: anggaran pendidikan, kondisi gedung sekolah, perlengkapan laboratorium, perpustakaan, manajemen sekolah, kurikulum, motivasi siswa dan mutu guru (Pannen \& Malati, 1997). Oleh sebab itu upaya peningkatan mutu pendidikan hendaknya dimulai dari peningkatan fungsi dan mutu setiap subsistem yang terkait. Apabila tidak dapat dilakukan secara bersamaan untuk seluruh subsistem maka hendaknya dilakukan dengan mengacu pada skala prioritas. Menurut Achmad (1994), mutu pendidikan ditentukan oleh empat faktor, yakni: (1) prasarana pendidikan, misalnya, gedung yang memadai sehingga siswa betah belajar di sekolah; (2) sarana pendidikan yakni: buku pelajaran, alat peraga, dan peralatan praktikum yang memadai; (3) kurikulum yang fleksibel sehingga mampu mengikuti perkembangan ilmu pengetahuan dan teknologi (iptek); dan (4) guru yang bermutu. Faktor guru merupakan faktor kunci, karena kehadiran guru yang bermutu dapat mengeliminir kekurangan dari tiga faktor yang lain.

Hasil penelitian dari United Nations Development Programme (UNDP) yang tahun 1999 disejumlah negara berkembang menyimpulkan bahwa guru memberikan kontribusi tertinggi (36\%) dalam capaian prestasi belajar, disusul manajemen (23\%), waktu belajar (22\%), dan sarana fisik (19\%). Pentingnya peranan guru dalam pendidikan diakui oleh semua pihak. Dikatakan bahwa guru merupakan faktor penentu utama bagi keberhasilan pendidikan. Undang-Undang No. 14 tahun 2005 menjelaskan bahwa tugas guru adalah mendidik, membelajarkan, membimbing, mengarahkan, melatih, menilai, dan mengevaluasi pada pendidikan anak usia dini, jalur pendidikan formal, pendidikan dasar, dan pendidikan menengah. Dalam menjalankan tugasnya, guru $h$ mempunyai empat kompetensi, yakni: (1) kompetensi pedagogik, yakni memahami potensi dan sanggup membimbing peserta didik, memahami teori belajar dan pembelajaran; (2) kompetensi kepribadian, yakni berwibawa, mantap, tenang, arif bijaksana, beraklak mulia, dan juga sanggup menjadi panutan; (3) kompetensi profesional, yakni mampu memahami bidang studi, memahami strategi pembelajaran, mampu merancang, melaksanakan pembelajaran, mengevaluasi hasil belajar; dan (4) kompetensi sosial, yakni terampil berkomunikasi dengan peserta didik, teman sejawat, dan pemangku kepentingan termasuk masyarakat secara luas.

Upaya peningkatkan mutu pendidikan kejuruan hendaknya diarahkan pada upaya peningkatan mutu guru SMK, mengingat faktor guru merupakan faktor kunci dalam 
proses penyelenggaraan pendidikan. Kompetensi guru merupakan indikator dari kualitas guru. Lantas pertanyaannya adalah bagaimanakah kompetensi guru SMK, utamanya guru SMK bidang keahlian teknologi dan rekayasa yang umumnya mereka berasal dari lulusan Fakultas Pendidikan Teknologi dan Kejuruan (FPTKIKIP) yang kemudian berubah menjadi Fakultas Teknik, termasuk Fakultas Teknik Universitas Negeri Jakarta (FT-UNJ). Berdasarkan deskripsi di atas, penelitian tentang kompetensi mahasiswa FT-UNJ untuk melaksanakan pembelajaran di SMK menjadi penting sebab mereka merupakan calon guru SMK.

Kompetensi guru dipengaruhi oleh banyak variabel, namun penelitian ini lebih fokus pada variabel-variabel yang diduga mempunyai pengaruh atau hubungan erat dengan kompetensi mahasiswa FT-UNJ dalam melaksanakan pembelajaran di SMK, yakni variabel: (1) konsep diri; (2) minat menjadi guru; dan (3) hasil belajar. Dipilihnya ketiga variabel tersebut dilandasi oleh tiga alasan, yakni sebagai berikut: (1) konsep diri seseorang terkait dengan rasa percaya diri sesorang dan rasa percaya diri ini merupakan modal penting bagi mahasiswa FT-UNJ sebagai calon guru SMK; (2) minat adalah daya dorong, sehingga mahasiswa FT-UNJ yang mempunyai minat dan keinginan yang kuat untuk menjadi guru SMK pada saatnya nanti diharapkan mereka berkompeten untuk menjadi guru yang baik; dan (3) mahasiswa FT-UNJ sebagai calon guru SMK hendaknya mempunyai pengetahuan yang luas, baik pengetahuan yang terkait dengan bidang studi maupun bidang keguruan. Luasnya pengetahuan itu akan tampak dari hasil belajar yang mereka peroleh.

Berdasarkan deskripsi di atas, maka masalah yang diangkat dalam penelitian ini dirumuskan sebagai berikut: (1) adakah hubungan antara konsep diri dengan kompetensi pembelajaran? (2) adakah hubungan antara minat menjadi guru dengan kompetensi pembelajaran? (3) adakah hubungan antara hasil belajar dengan kompetensi pembelajaran? dan (4) adakah hubungan antara konsep diri, minat menjadi guru, dan hasil belajar secara bersama-sama dengan kompetensi mahasiswa FT-UNJ untuk melaksanakan pembelajaran di SMK?

Dari rumusan masalah tersebut di atas, maka tujuan dari penelitian adalah upaya untuk memperoleh gambaran mengenai eratnya hubungan konsep diri, minat menjadi guru, dan hasil belajar dengan kompetensi mahasiswa FT-UNJ untuk melaksanakan pembelajaran di SMK. Penelitian ini penting untuk dilakukan dan hasilnya diharapkan mempunyai nilai manfaat, baik secara teoretis maupun secara praktis. Secara teoretis, hasil penelitian ini diharapkan dapat memberikan informasi bagi perkembangan ilmu pengetahuan di bidang teknologi pendidikan, utamanya tentang keterkaitan varaibel konsep diri, minat menjadi guru, dan hasil belajar dengan kompetensi mahasiswa FT-UNJ untuk melaksanakan pembelajaran di SMK. Adapun secara praktis hasil penelitian ini diharapkan bermanfaat untuk: (1) referensi dalam rangka meningkatkan kompetensi pembelajaran mahasiswa dari LPTK; (2) bahan masukan bagi stake-holder dalam merekut lulusan LPTK untuk menjadi guru; (3) sumber pengetahuan bagi mahasiswa dalam upaya meningkatkan kompetensinya; (4) informasi awal untuk melakukan penelitian lebih lanjut tentang kompetensi mahasiswa FT-UNJ untuk melaksanakan pembelajaran di SMK.

\section{METODE}

Penelitian ini dilakukan di Fakultas Teknik Universitas Negeri Jakarta (FT-UNJ) dan di sekolah menengah kejuruan sebagi tempat mahasiswa FT-UNJ melakukan kegiatan praktik pengalaman lapangan atau praktik mengajar. Lokasi SMK tersebar di seluruh wilayah DKI Jakarta kecuali pulau seribu. Data penelitian untuk variabel konsep diri dan minat menjadi guru, diukur dengan instrumen berupa kuesioner atau angket dengan model skala likert dengan jumlah butir 32 dan 30.

Data penelitian untuk variabel kompetensi pembelajaran diukur dengan instrumen berupa lembar penilaian yakni angka penilaian kompetensi guru (APKG) yang 
dikeluarkan oleh Pusat PPL-UNJ. Validitas butir setiap instrumen dianalisis dengan teknik analisis korelasi product moment dan jumlah butir yang dinyatakan valid untuk instrumen variabel konsep diri sebanyak 31 butir dan untuk instrumen variabel minat menjadi guru hanya 28 butir. Sedangkan reliabilitas atau keandalan instrumen dihitung dengan rumus alpha cronbach dan besarnya koefisien alpha instrumen konep diri adalah 0,9179 dan untuk instrumen variabel minat menjadi guru adalah 0,9386 .

Untuk menguji hipotesis yang diajukan di digunakan teknik analisis statistik korelasi sederhana dan korelasi ganda. Adapun untuk mengetahui keberartian regresi dan besarnya kontribusi yang diberikan oleh masingmasing variabel bebas terhadap variabel terikat digunakan teknik analisis regresi sederhana dan regresi ganda. Namun sebelum dilakukan uji hipotesis maka terlebih dahulu dilakukan uji persyaratan analisis, yakni uji normalitas yang dilakukan dengan uji Lilliefors dan uji homogenitas yang dilakukan dengan uji barlett.

\section{HASIL DAN PEMBAHASAN}

\section{A. Deskripsi Data}

Penelitian ini mencakup empat variabel, yakni: konsep diri, minat menjadi guru, prestasi belajar, dan kompetensi pembelajaran. Adapun jumlah sampel dalam penelitian ini sebanyak 60 orang..

Tabel 1. Hasil Perhitungan Gejala Pemusatan

\begin{tabular}{|c|c|c|c|c|c|}
\hline Variabel Penelitian & $\mathrm{n}$ & Mean & $\begin{array}{c}\text { Medi } \\
\text { an }\end{array}$ & $\begin{array}{l}\text { Mo } \\
\text { dus }\end{array}$ & $\begin{array}{l}\text { Simp. } \\
\text { Baku }\end{array}$ \\
\hline $\begin{array}{c}\text { Kompetensi } \\
\text { Pembelajaran (Y) }\end{array}$ & 60 & 80,23 & 80 & 80 & 5,91 \\
\hline Konsepn Diri $\left(\mathrm{X}_{1}\right)$ & 60 & 76,58 & 75 & 75 & 6,65 \\
\hline Minat Menjadi Guru $\left(\mathrm{X}_{2}\right)$ & 60 & 78,25 & 78 & 69 & 7,29 \\
\hline Hasil Belajar $\left(\mathrm{X}_{3}\right)$ & 60 & 78,55 & 80 & 80 & 5,53 \\
\hline
\end{tabular}

\section{B. Hasil Analisis Diskriptif}

Rangkuman hasil analisis deskriptif yang dilakukan terhadap data penelitian dari empat variabel yang diteliti, yakni: variabel kompetensi pembelajaran, variabel konsep diri, variabel minat menjadi guru, dan variabel hasil belajar masing-masing dipaparkan pada tabel 2, 3, 4, dan 5 di bawah ini.
Tabel 2. Rangkuman Data Variabel Kompetensi

\begin{tabular}{ccccc}
\multicolumn{5}{c}{ Pembelajaran } \\
\hline No. & $\begin{array}{c}\text { Jumlah } \\
\text { Responden }\end{array}$ & $\begin{array}{c}\text { Persen } \\
(\%)\end{array}$ & Skor & $\begin{array}{c}\text { Konsep } \\
\text { Diri }\end{array}$ \\
\hline 1 & 5 & 8,3 & $>89,09$ & Baik \\
2 & 21 & 35 & $80,23-89,09$ & Cukup \\
3 & 29 & 48,4 & $71,37-80,23$ & Kurang \\
4 & 5 & 8,3 & $<71,37$ & Sangat \\
Jml & 60 & 100 & & Kurang \\
\hline
\end{tabular}

Tabel 3. Rangkuman Data Variabel Konsep Diri

\begin{tabular}{ccccc}
\hline No. & $\begin{array}{c}\text { Jumlah } \\
\text { Responden }\end{array}$ & $\begin{array}{c}\text { Persen } \\
(\%)\end{array}$ & Skor & $\begin{array}{c}\text { Konsep } \\
\text { Diri }\end{array}$ \\
\hline 1 & 1 & 1,7 & $>86,56$ & Tinggi \\
2 & 40 & 66,7 & $76,58-86,56$ & Sedang \\
3 & 17 & 28,3 & $66,60-76,58$ & Kurang \\
4 & 2 & 3,3 & $<66,60$ & Rendah \\
Jml & 60 & 100 & & \\
\hline
\end{tabular}

Tabel 4. Rangkuman Data Variabel Minat Menjadi

\begin{tabular}{ccccc}
\multicolumn{5}{c}{ Guru } \\
\hline No. & $\begin{array}{c}\text { Jumlah } \\
\text { Responden }\end{array}$ & $\begin{array}{c}\text { Persen } \\
(\%)\end{array}$ & Skor & $\begin{array}{c}\text { Minat } \\
\text { Menjadi } \\
\text { Guru }\end{array}$ \\
\hline 1 & 5 & 8,3 & $>89,19$ & Tinggi \\
2 & 23 & 38,3 & $78,25-89,19$ & Sedang \\
3 & 31 & 51,7 & $67,32-78,25$ & Kurang \\
4 & 1 & 1,7 & $<67,32$ & Rendah \\
Jml. & 60 & 100 & & \\
\hline
\end{tabular}

Tabel 5. Rangkuman Data Variabel Hasil Belajar

\begin{tabular}{ccccc}
\hline No. & $\begin{array}{c}\text { Jumlah } \\
\text { Responden }\end{array}$ & $\begin{array}{c}\text { Persen } \\
(\%)\end{array}$ & Skor & $\begin{array}{c}\text { Hasil } \\
\text { Belajar }\end{array}$ \\
\hline 1 & 3 & 5 & $>86,85$ & Tinggi \\
2 & 20 & 33,3 & $78,55-86,55$ & Sedang \\
3 & 27 & 45 & $70,25-78,55$ & Kurang \\
4 & 10 & 16,7 & $<70,25$ & Rendah \\
Jml & 60 & 100 & & \\
\hline
\end{tabular}

\section{Uji Persyaratan Analisis}

1. Uji Normalitas

Uji normalitas data dilakukan terhadap galat taksiran regresi $\mathrm{Y}$ atas $\left(\mathrm{X}_{1}\right),\left(\mathrm{X}_{2}\right)$, dan $\left(\mathrm{X}_{3}\right)$ dengan teknik uji Lilliefors pada taraf signifikansi $\partial=0,05$.

Tabel 6. Rangkuman Hasil Uji Normalitas Data

\begin{tabular}{ccccccc}
\hline No & $\begin{array}{c}\text { Galat } \\
\text { Taksiran } \\
\text { Regresi }\end{array}$ & Lhitung & $\alpha=0,05$ & $\alpha=0,01$ & keterangan & $\begin{array}{c}\text { Kesimp } \\
\text { ulan }\end{array}$ \\
\hline 1 & $\begin{array}{c}\text { Yatas } \\
\mathrm{X}_{1}\end{array}$ & 0,0987 & 0,1144 & 0,1331 & $\mathrm{H}_{0}$ diterima & Normal \\
2 & $\begin{array}{c}\text { Yatas } \\
\mathrm{X}_{2}\end{array}$ & 0,0757 & 0,1144 & 0,1331 & $\mathrm{H}_{0}$ diterima & Normal \\
3 & $\begin{array}{c}\text { Yatas } \\
\mathrm{X}_{3}\end{array}$ & 0,0454 & 0,1144 & 0,1331 & $\mathrm{H}_{0}$ diterima & Normal \\
\hline
\end{tabular}

\section{Hasil Uji Homogenitas Populasi}

Uji homogenitas populasi dilakukan terhadap varians pengelompokan $\mathrm{Y}$ atas $\left(\mathrm{X}_{1}\right),\left(\mathrm{X}_{2}\right)$, dan $\left(\mathrm{X}_{3}\right)$ dengan teknik uji Bartlett pada taraf signifikansi $\partial=0,05$.

Tabel 7. Rangkuman Hasil Uji Homogenitas

\begin{tabular}{ccccc}
\multicolumn{5}{c}{ Populasi. } \\
\hline Variabel Y Atas & $\mathrm{dk}_{\mathrm{i}}$ & $\mathrm{X}_{\text {hitung }}$ & $\mathrm{X}_{\text {tabel }}^{2}$ & Kesimpulan \\
\hline Konsep Diri $\left(\mathrm{X}_{1}\right)$ & 14 & 16,964 & 23,685 & Homogen \\
Minat Menjadi & 17 & 20,968 & 27,586 & Homogen \\
Guru $\left(\mathrm{X}_{2}\right)$ & & 19,662 & 22,364 & Homogen \\
Hasil Belajar $\left(\mathrm{X}_{3}\right)$ & 13 & 19,6
\end{tabular}




\section{Pengujian Hipotesis}

Hipotesis dalam penelitian ini diuji dengan teknik analisis regresi dan korelasi. Untuk hipotesis pertama, kedua, dan ketiga diuji dengan teknik analisis regresi sederhana, korelasi sederhana, dan korelasi parsial. Sedang-kan untuk hipotesis keempat diuji dengan teknik analisis regresi jamak dan korelasi jamak.

\section{Hubungan Konsep Diri dan Kompetensi Pembelajaran}

Hipotesis pertama menyatakan bahwa ada hubungan positif dan signifikan antara konsep diri $\left(\mathrm{X}_{1}\right)$ dengan kompetensi pembelajaran (Y). Dari Hasil analisis regresi yang telah dilakukan, maka hubungan antara konsep diri $\left(\mathrm{X}_{1}\right)$ dengan kompetensi pembelajaran $(\mathrm{Y})$ dapat digambarkan melalui persamaan regresi $\hat{\mathrm{Y}}=35,412+0,593 \mathrm{X}_{1}$. Adapun uji signifikansi persamaan regresi dan linea-ritas dilakukan dengan uji F.

Tabel 8. Rangkuman Hasil Anova Persamaan regresi

\begin{tabular}{|c|c|c|c|c|c|c|}
\hline \multirow{2}{*}{$\begin{array}{l}\text { Sumber } \\
\text { Varians }\end{array}$} & \multirow{2}{*}{ Dk } & \multirow[b]{2}{*}{ JK } & \multirow{2}{*}{ RJK } & \multirow[b]{2}{*}{$F_{\text {hitung }}$} & \multicolumn{2}{|c|}{$\mathrm{F}_{\text {tabel }} \operatorname{pada} \alpha$} \\
\hline & & & & & 0,05 & 0,01 \\
\hline Total & 60 & 388302 & 6471,7 & & & \\
\hline $\begin{array}{l}\text { Regresi } \\
\text { (a) }\end{array}$ & 1 & 386243,267 & 386243,267 & & & \\
\hline $\begin{array}{l}\text { Regresi } \\
\text { (b/a) }\end{array}$ & 1 & 323,086 & 323,086 & $10,826 * *$ & 4,00 & 7,08 \\
\hline Sisa & 58 & 1735,647 & 29,925 & & & \\
\hline $\begin{array}{c}\text { Tuna } \\
\text { Cocok }\end{array}$ & 21 & 339,511 & 16,167 & $0,428^{\mathrm{ns}}$ & 1,80 & 2,23 \\
\hline Galat & 37 & 1396,136 & 37,33 & & & \\
\hline
\end{tabular}

\section{Hubungan Minat Menjadi Guru dan} Kemampuan Pembelajaran

Hipotesis kedua menyatakan bahwa terdapat hubungan positif dan signifikan antara minat mahasiswa FT-UNJ untuk menjadi guru $\left(\mathrm{X}_{2}\right)$ dengan kemampuan pembelajaran din SMK (Y). Dari Hasil analisis regresi, tampak bahwa hubungan antara minat menjadi guru $\left(\mathrm{X}_{2}\right)$ dengan kemampuan pembelajaran (Y) dapat digambarkan melalui persamaan regresi $\hat{Y}=$ $59,014+0,272 \mathrm{X}_{2}$. Uji signifikansi regresi dan linearitas dilakukan dengan uji $\mathrm{F}$.

Tabel 9. Rangkuman Hasil Anava Persamaan Regresi $\hat{\mathrm{Y}}=59,014+0,272 \mathrm{X}_{2}$

\begin{tabular}{cccccccc}
\hline $\begin{array}{c}\text { Sumber } \\
\text { Varians }\end{array}$ & \multirow{2}{*}{$\mathrm{dk}$} & \multirow{2}{*}{$\mathrm{JK}$} & \multirow{2}{*}{$\mathrm{RJK}$} & $\mathrm{F}_{\text {hitung }}$ & \multicolumn{2}{c}{$\mathrm{F}_{\text {tabel }}$ pada $\alpha$} \\
\cline { 6 - 7 } & & & & & 0,05 & 0,01 \\
\hline $\begin{array}{c}\text { Total } \\
\text { Regresi }\end{array}$ & 60 & 388302 & 6471,17 & & & \\
$\quad$ (a) & 1 & 386243,267 & 386243,267 & & & \\
$\begin{array}{c}\text { Regresi } \\
\text { (b/a) }\end{array}$ & 1 & 234,955 & 324,955 & $7,472^{*}$ & 4,00 & 7,08 \\
$\begin{array}{c}\text { Sisa } \\
\text { Tuna }\end{array}$ & 58 & 1823,778 & 31,444 & & & \\
Cocok & 21 & 279,411 & 11,624 & $0,256^{\text {ns }}$ & 1,80 & 2,23 \\
Galat & 37 & 1544,367 & 45,423 & & & \\
\hline
\end{tabular}

\section{Hubungan Hasil Belajar dan Kompetensi Pembelajaran}

Hipotesis ketiga menyatakan bahwa ada hubungan positif dan signifikan antara hasil belajar $\left(\mathrm{X}_{3}\right)$ dengan kompetensi pembelajaran (Y). Dari hasil analisis regresi yang telah dilakukan, maka hubungan antara hasil belajar $\left(\mathrm{X}_{3}\right)$ dan kompe-tensi pembelajaran (Y) dapat digambarkan melalui persamaan regresi $\hat{Y}=44,305+0,456 \mathrm{X}_{3}$. Sedangkan untuk uji signifikansi persamaan regresi dan linearitasnya dilakukan dengan uji $\mathrm{F}$.

Tabel 10. Rangkuman Hasil Anava Persamaan Regresi $\hat{Y}=44,305+0,456 \mathrm{X}_{3}$

\begin{tabular}{lllllll}
\hline Sumber & $\mathrm{dk}$ & $\mathrm{JK}$ & $\mathrm{RJK}$ & $\mathrm{F}_{\text {hitung }}$ & \multicolumn{2}{c}{$\mathrm{F}_{\text {tabel }}$ Tabel $\alpha$} \\
Varians & & & & & 0,05 & 0,01 \\
\hline Total & 60 & 388302 & 6471,7 & & & \\
Regresi (a) & 1 & 386243,267 & 386243,267 & & & \\
Regresi (b/a) & 1 & 346,267 & 346,712 & $11,746^{* *}$ & 4,00 & 7,08 \\
Sisa & 58 & 1712,021 & 29,518 & & & \\
Tuna Cocok & 17 & 626,665 & 36,733 & $0,977^{\text {ns }}$ & 1,82 & 2,35 \\
Galat & 41 & 1085,356 & 37,733 & & & \\
\hline
\end{tabular}

4. Hubungan Minat Menjadi Guru, Konsep Diri, dan Hasil Belajar dengan Kompetensi Pembelajaran.

Hipotesis keempat menyatakan terdapat hubungan positif dan signifikan antara konsep diri $\left(\mathrm{X}_{1}\right)$, minat menjadi guru $\left(\mathrm{X}_{2}\right)$ dan hasil belajar $\left(\mathrm{X}_{3}\right)$ secara bersama-sama dengan kompetensi pembelajaran (Y). Dari Hasil analisis regresi jamak diproleh arah regresi untuk $\mathrm{a}_{1}=0,428 ; \mathrm{a}_{2}=-0,001 ;$ dan $\mathrm{a}_{3}=0,576$ dengan konstanta $\mathrm{a}_{0}=42,278$, maka bentuk hubungan antara konsep diri $\left(\mathrm{X}_{1}\right)$, minat menjadi guru $\left(\mathrm{X}_{2}\right)$ dan hasil belajar $\left(\mathrm{X}_{3}\right)$ secara bersama-sama dengan kompetensi pembelajaran (Y) dapat dinyatakan dengan persamaan regresi $\hat{\mathrm{Y}}=42,278+0,428 \mathrm{X}_{1}$ $0,001 \mathrm{X}_{2}+0,576 \mathrm{X}_{3}$. Uji signifikansi persamaan regresi dilakukan dengan uji $\mathrm{F}$.

Tabel 11. Rangkuman Hasil Analisis Anava Regresi Jamak $X_{1}, X_{2}, X_{3}-Y$

\begin{tabular}{ccccccc}
\hline Sumber & \multirow{2}{*}{$\mathrm{dk}$} & \multirow{2}{*}{$\mathrm{JK}$} & \multirow{2}{*}{ RJK } & \multirow{2}{*}{ F hitung } & \multicolumn{2}{c}{ F pada $\alpha$} \\
\cline { 6 - 7 } Varians & & & & & 0,05 & 0,01 \\
\hline $\begin{array}{c}\text { Regresi } \\
\text { (b/a) }\end{array}$ & 3 & 865,543 & 288,514 & 9,307 & 2,78 & 0,01 \\
$\begin{array}{c}\text { Sisa } \\
\text { Total }\end{array}$ & 56 & 1735,961 & 30,999 & & & 4,16 \\
Reduksi & 59 & 2621,504 & - & - & - & - \\
\hline
\end{tabular}

\section{E. Temuan penelitian}

1. Berdasarkan deskripsi data dapat diketahui bahwa: (a) kompetensi mahasiswa FT-UNJ untuk pembelajaran di SMK adalah rendah, karena mayoritas $(56,6 \%)$ respoden berada di bawah rata-rata; (b) konsep diri mahasiswa FT-UNJ adalah 
rendah, karena mayoritas $(56,7 \%)$ respoden berada di bawah rata-rata; (c) minat mahasiswa FT-UNJ untuk menjadi guru SMK adalah rendah, karena mayoritas $(53,4 \%)$ respoden berada di bawah rata-rata; dan (d) hasil belajar mahasiswa FT-UNJ adalah tinggi, karena mayoritas $(56,7 \%)$ responden berada di atas rara-rata.

2. Dari hasil analisis korelasi sederhana dapat diketahui bahwa ada hubungan positif dan signifikan antara konsep diri mahasiswa FT-UNJ dengan kompetensi pembelajaran di SMK dengan koefisien korelasi $\mathrm{r}_{\mathrm{y} 1}=$ 0,569 .

3. Dari hasil analisis korelasi sederhana dapat diketahui bahwa ada hubungan positif dan signifikan antara minat mahasiswa FTUNJ menjadi guru SMK dengan kompetensi pembelajaran di SMK dengan koefisien korelasi $\mathrm{r}_{\mathrm{y} 2}=0,319$.

4. Dari hasil analisis statistik korelasi sederhana dapat diketahui bahwa ada hubungan positif dan signifikan antara hasil belajar mahasiswa FT-UNJ dengan kompetensi pembelajaran di SMK dengan koefisien korelasi $r_{\mathrm{y} 3}=0,427$.

5. Dari hasil analisis korelasi jamak, diketahui bahwa ada hubungan positif dan signifikan antara konsep diri, minat menjadi guru dan hasil belajar dengan kompetensi mahasiswa FT-UNJ dalam pembelajaran di SMK dengan koefisien korelasi $r_{\mathrm{y} .123}=0,575$.

\section{KESIMPULAN DAN SARAN Kesimpulan}

Pertama, hasil analisis korelasi sederhana dan korelasi parsial menunjukkan bahwa terdapat hubungan positif antara konsep diri dan kompetensi pembelajaran dengan keeratan hubungan tinggi dan mampu memberikan kontribusi sebesar $51,70 \%$. Hal ini menunjukkan bahwa kompetensi mahasiswa FT-UNJ untuk melaksanakan pembelajaran di SMK masih dapat ditingkatkan lagi dengan cara meningkatkan konsep diri yang mereka miliki.

Kedua, hasil analisis korelasi sederhana dan korelasi parsial menunjukkan bahwa terdapat hubungan positif antara minat menjadi guru dan kompetensi pembelajaran dengan keeratan hubungan sedang dan mampu memberikan kontribusi sebesar $47,70 \%$. Hal ini berarti bahwa kompetensi mahasiswa FT-UNJ untuk malaksanakan pembelajaran di SMK dapat ditingkatkan dengan meningkatkan minat mereka untuk menjadi guru SMK.

Ketiga, hasil analisis korelasi sederhana dan korelasi parsial menunjukkan bahwa terdapat hubungan positif antara variabel hasil belajar dengan variabel kompetensi pembelajaran dengan keeratan hubungan sedang dan mampu memberikan kontribusi sebesar 26,63\%. Hal ini berarti bahwa kompetensi mahasiswa FT-UNJ untuk malaksanakan pembelajaran di SMK dapat ditingkatkan dengan cara meningkatkan hasil belajar mereka.

Keempat, hasil analisis korelasi jamak menunjukkan bahwa terdapat hubungan positif antara konsep diri, minat menjadi guru, dan hasil belajar secara bersama-sama dengan kompetensi pembelajaran dengan keeratan hubungan yang cukup tinggi dan mampu memberikan kontribusi sebesar $68,39 \%$. Hal ini berarti bahwa kompetensi mahasiswa FTUNJ untuk melaksanakan pembelajaran di SMK dapat ditingkatkan dengan cara meningkatkan secara bersama-sama (simultan) variabel konsep diri, minat menjadi guru, dan hasil belajarnya.

\section{Saran}

Pertama, kepada peneliti lain agar melakukan penelitian sejenis dengan variabel bebas yang berbeda.

Kedua, hendaknya: (1) mahasiswa FTUNJ sebagai calon guru agar terus berupaya meningkatkan konsep diri dan rasa percaya diri; (2) dosen FT-UNJ agar lebih berperan aktif dalam menciptakan lingkungan belajar yang kondu-sif dan terus meningkatkan mutu proses pembelajarannya; dan (3) pimpinan jurusan, fakultas, dan universitas agar terus meningkatkan mutu pengelolaan lembaga dengan menonjolkan ciri-ciri lembaga pendidikan tenaga kependidikan.

Ketiga, hendaknya: (1) mahasiswa FTUNJ sebagai calon guru agar berupaya 
meningkatkan minatnya untuk menjadi guru dengan cara mengikuti berbagai kegiatan yang terkait dengan profesi guru termasuk mengikuti kegiatan PPL dengan sungguhsungguh; dan (2) dosen-dosen FT-UNJ agar berperan aktif untuk membangkitkan minat mahasiswa untuk mencitai profesi guru, mengingat akhir-akhir ini ada kecenderungan bahwa mereka kurang tertarik pada profesi guru meskipun mereka kuliah di lembaga pencetak guru.

Keempat, mahasiswa, dosen, dan pimpinan FT-UNJ secara bersama-sama berupaya: (1) meningkatkan mutu materi dan mutu proses pembelajaran, (2) meningkatkan mutu dan jumlah peralatan praktikum; dan (3) meningkatkan sarana dan prasarana pendukung kegiatan pembelaaran.

Kelima, mahasiswa FT-UNJ berupaya meningkatkan konsep diri, minat menjadi guru, dan hasil belajar.

\section{DAFTAR PUSTAKA}

Ananta, A. 1988. Produktivitas dan Daya Serap terhadap Pekerja. Majalah Definisi. Jakarta: Demografi Indonesia Volume 30.

Anastasi, A. 1989. Field of Apllied

Psykology. Tokyo: McGraw-Hill

Kogakusha, Ltd.

Anonim. 2006. Harian Kompas. Jakarta:

Gramedia.

Anonim.1999/2000. Petunjuk Teknis

Kelompok Pemuda Produktif. Jakarta:

Direktorat Jendral Diklusepora, Depdiknas.

Dwivedi, Anju. 2003. Metodologi Pelatihan

Partisipatif. Yogyakarta: Pondok Edukasi.

Anderson, Lorin W. And Krethwohl, David

R. 2001. A Taxonomy or learning,

Teaching, and Assessing, A Revision of

Bloom'S Taxonomy of Educational Objectives. New York: Addition Wesley Longman, Inc.

Arikunto, Suharsimi 1988, Organisasi dan Administrasi Pendidikan Teknologi dan Kejuruan, Jakarta: Dirjen Dikti Depdiknas. Burnham John West, Bradbury Ingrid, O’Neill John, 2002. Performance Management in Schools, London : Pearson Education.
Cenci Louis dan Weaver Gilber G, 1968. Teaching Occupational Skill, Second Editions, New York: Pitman Publishing Corporation.

Griffin, Ricky W \& Gregory Moorhead. 1992. Organizational Behavior, Boston: Houghton Publishing.

Gunarsa, Y.S.D. dan Gunarsa, S.D. 1998. Psikologi untuk membimbing. Jakarta: BPK Gunung Jati.

Koswara, Yayah. 1999. Kebijakan Dikti tentang program Pengembangan Budaya Kewiraushaan. Pelatihan Dosen UNJ dalam Rangka Pengembangan Budaya Kewirausahaan Melalui Integratif Bahan Ajar (IBA). Jakarta: UNJ.

Lansor, Milton E. 1972. Teaching Related Subyects in Trade and Industrial and Technical Edication Ohio: Charles E Merrill Publishing.

Leighbody, Gerald B dan Kidd Donald M,. 1968. Methods of Teacheng Shop and Technical Subjects, New York: Delmark Publisher.

Pekerti, Anugerah. 1999. Filosofi Kewirausahaan. Pelatihan Dosen UNJ dalam Rangka Pengembangan Budaya Kewirausahaan Melalui Integratif Bahan Ajar. Jakarta: UNJ.

Reddy R. S. 1996. Principles and Practices of Teacher Education. Delhi Rajat Publication.

Sarwono, Sarlito Wirawan. 1998. Teori Teori Psikologi Pendidikan, Jakarta: PT. Raja Grafindo Persada.

Suradjiman. 1980. Peningkatan Pendidikan Kejuruan Melalui Pembinaan Jiwa Wiraswasta. Analisis Pendidikan. Volume 2.

Sutari, Imam Barnadib.1992. Identifikasi Proses dan Peristiwa Kependidikan. Yogyakarta: Penerbit Fakultas Psikologi UGM 